\title{
HYDRAULIC AND ECOLOGICAL CHANGES UNDER DRAINAGE GATE OPERATIONS WITH COUPLED MODEL SCHISM-COSINE IN SAEMANGEUM BASIN, KOREA
}

\author{
Hyung Ju YOO ${ }^{1}$, Seokil JEONG², Dong Hyun KIM¹, Seung Oh LEE ${ }^{*}$ \\ ${ }^{1}$ Department of Civil \& Environmental Engineering, Hongik University, Seoul, Korea \\ ${ }^{2}$ Water Resources Management Department, Nakdonggang River Regional Head Office, Daegu, Korea
}

Received 28 May 2020; accepted 17 March 2021

\author{
Highlights \\ Operation of drainage gate was well implemented within coupled model SCHISM-CoSiNE. \\ Concentrations of DO, T-N and T-P were affected by designated water level. \\ $>$ Numerical accuracy was enhanced by field data for optimal designated water level. \\ Designated water level was examined to enforce the water quality management.
}

\begin{abstract}
The drainage gates have been controlled for desalination under normal conditions and flood defense in Saemangeum basin, Korea. Recently, it became an issue that the gates have been opened not to deteriorate water quality in the lake. It is, thus, necessary to precisely estimate the changes of water quality characteristics, especially DO, phosphate and nitrate, in the lake according to various gate operations. In this study, Semi-implicit Cross-scale Hydroscience Integrated System Model and Carbon, Silicate, Nitrogen Ecosystem model (SCHISM-CoSiNE) which is cable to simulate dynamic exchange such as gate operation conditions was utilized to obtain reliable and reasonable results including hydrodyanamic and environmental variables. For the verification, the measured data at 6 locations in Saemangeum basin was used to compare incluidng temperatue and salintiy from 2016 and each relative error became small enough to show high accurary. Also, under various scenarios by changing the designated water surface elevation on flood seasons, this model has been applied to present the best designated water surface elevation in terms of both water quality and water supply in the Saemangeum basin. It becomes possbile to show reliable guidance for dynamic operations and environmental changes with this model as requested in near future.
\end{abstract}

Keywords: gate operation, water quality, 3D numerical model, SCHISM, CoSiNE, designated water surface elevation.

\section{Introduction}

The Saemangeum basin which is located central west coast of Korea (Latitude: 354928 N Longitude: $12690 \mathrm{E}$ ), has the longest sea dikes on the world. The dikes damed a natural esturay system where fresh water from two river system (Mangyeonggang and the Dongjingang Rivers) met West Sea of Korea. The construction of the sea dikes dramtically changed hydraulic and enviromental system inner these dikes and now the system behaviors like a freshwater lake or reservoir (Liu et al., 2018). However, the lack of water exhange between the rivers and ocean has led to reduction of Biochemical Oxygen Demand (BOD) and Dissolved Oxygen (DO) which causes multifaceted water quality problems. For instance, the Isahaya bay in Japan, similar to Saemangeum basin, became worsened water quality after the construction of the sea dikes. Even Japan tried to improve water quality with limited success (Yokoyama \& Kyozuka, 2003). The Netherlands had the effect of eliminating the inflow of seawater after the Haringvliet dam construction, which was a part of the Delta project, but the water quality was deteriorated by the decrease of flow velocity (Stuyfzand et al., 2004). In the Tuckombil Canal in Australia, the sluice gates were installed to prevent flood inundation, but the management facilities became obsolete and water quality also deteriorated sharply (Cavanagh et al., 2006). Finally, in a lake formed by artificially obstructing the river, the amount of organic matter which

*Corresponding author. E-mail: seungoh.lee@hongik.ac.kr 
was put into the lake increased and the contaminants were accumulated because flow velocity became slowed. The decrease of salinity due to the reduction of tidal current or the increase of temperature was also one of the causes to occur those results. The similar phenomenon occurred in Sihwa Lake, Korea in 1994.

In Sihwa Lake which was planned to supply agricultural water after the construction of the sea dike, the surface layer and the bottom layer were stratified due to salt driven density differences which inhabited vertical circulations leading to complicated water quality issues (Park et al., 1997). To alleviate those waer quality issues, the Master Plan was changed to inflow the seawater in the lake (Korea Rural Community Corporation [KRCC], 2006). The Saemangeum basin is located not far from Sihwa Lake, and water quality problems have been constantly raised since the completion of the construction in 2001. Even after governmental financial committment and its engineering measures such as the installation of sedimentation facilities, phosphorus treatment facilities and sewage disposal facilities were strongly supported, there has been limited improvement of the water quality standard by the measures themselve, but the target standard were laboriously met in combination of seawater cicurlating the system by operation of Sinsi gate and Garyeok gate (KRCC, 2016).

In this study, we analyzed the quantatively change of water quality to provide more fundamental measures, for instnace altering designated water surface elevations regulated by Saemangeum basin Master Plan (Korean Government, 2011) in which land reclamation would be conducted after changing completely freshwater system inside dikes. The coupled SCHISM-CoSiNE model was utilized to examine the changes of water quality according to dynamic changes by drainage gate operation. The specific conditions for modelling of drainage gate operation was included to simulate the concentration fluxes of major water quality variables, including nitrate and phosphate. Finally, we evaluated our study results by comparing with the water quality standards from the Framework act on environmental policy (Ministry of Environment, Republic of Korea, 2019) in Korea. We also provided the possible optimal solutions about water quality problem in the Saemangeum basin.

\section{Literature review}

\subsection{Hydraulic characteristics studies}

The residence time and exhange rate of contaminants, and the process of stratification are closely related to the hydraulic characteristics in a lake which should be examined prior to undertaking any effort to improve water quality in the lake. For the Saemangeum basin, Jeong et al. (2017) performed the sensitiviy analysis on hydraulic characteristics by dredging in upstream of abrupt expansion region and found the relationship between sediment mechanism at dredging section and hydraulic characteristics in upstream region. Suh and Cho (2007) used the 2-D
Advanced circulation model for oceanic, coastal and estuarine waters (ADCIRC) and analyzed hydraulic chnages on the Saemangeum basin with the completion of the sea dike. Jeong et al. (2018b) simulated the hydraulic characteristics of the Saemangeum and Mangyeonggang river and Dongjingang river with climate change scenarios using Delft3D model. And Bae et al. (2017) simulated the change of residence time in Sihwa lake under gate operation using the Lagrangian Particle Tracking (LPT) model. However, the operation of drainage gates were not represented in their models and downstream conditions were set by historical seawater level data. And the operation rules that even though the inner water surface elevation was higher than the outer sea level, the gate was closed when the inner water surface elevation was lower than the designated water surface elevation, was difficult to simulate without the specific inner boundary conditions in the previous numerical models. In order to reproduce the bi-directional flow of the estuary and the artificial lake connected through the drainage gate, Zigic et al. (2005) presented a method applying the boundary conditions in hydraulic structures. Jinqiong et al. (2020) introduced the inside boundary condition of gate to reproduce the bidirectional flow. And Weng et al. (2020) also presented a method applying the sluice control boundary considering the sea level. Therefore, the bi-directional flow through the drainage gates is reproduced with specific boundary condition using the field data such as operation time log of gates, the sea level and designated water surface elevation in this study.

\subsection{Water quality studies}

Most water quality researches have been conducted by analyzing the measured field data or by simulating with computational models. The Saemangeum basin has been also studied based on two kinds of methods. First, the KRCC set up 6 measurement stations to collect field data including hydraulic and water qaulity characteristics. Suh and Lee (2008) used the environmental fluid dynamics code (EFDC) model to analyze the changes of water quality in the Saemangeum basin. The KRCC conducted an environmental impact study based on its own surveyed data for 16 years from 1991 to 2006. In addition, the corporation (KRCC, 2006) developed the modified stream water quality model and the water quality analysis simulation program (WASP5) model to predict water quality of watershed and lake in the Saemangeum basin. Jeong and Yang (2015) predicted trends and future water quality based on 40 field survey data from 2002 to 2010 . The salinity, chlorophyll a, dissolved inorganic nitrogen (DIN) and suspended particulate matter (SPM) were investigated. They confirmed that the organic matter was accumulated, and $\mathrm{NH}_{4}-\mathrm{N}$ was increased after the construction of the sea dike. It was also found that hypoxic conditions were getting more pronounced after the construction. Kim et al. (2016) examined a potential improvment if a new dam was consturcted at a upper site to capture inflow and 
used it to meet water quality target standards in the basin. Jeong et al. (2018a) simulated the water quality in the Saemangeum basin considering the operation of drainage gates using the Delft3D-WAQ (WAter Quality) model.

Even though numerous attempts have been conducted to review water quality issues in Saemangeum basin, most previous studies were undertaken to demonstrate quantitively change of water quality before and after the construction of the sea dike. And the structural measures such as the installation of sedimentation facilities, phosphorus treatment facilities suggested in previous studies were founded to be an insufficient solution to alleviate the water quality issues in this basin. Jinqiong et al. (2020) examined the impact of gate operation to improve the water quality in Yongding New River. And Saadatpour (2020) reviewed the effect of improving water quality in Meimeh River basin under various upstream saline inflow control scenarios and suggested the optimal reservoir operation.

In this study, the non-structural measure, altering the designated water surface elevation to control the gate operation for improving the water quality, was suggested to alleviate the water quality issues in Saemangeum basin and examined as a solution to make up for the limitations of water quality improvement through structural measures. And future scenario under the complete of Saemangeum basin Master Plan which was not considered in most previous studies, was applied on various designated water surface elevation conditions.

\section{Numerical model}

\subsection{SCHISM}

The hydraulic simulations are performed by the Semi-implicit Cross-scale Hydroscience Integrated System Model (SCHISM) (Zhang et al., 2015, 2016) which is completely modified model from the Semi-implicit Eulerian-Lagrangian Finite-Elemnt model (SELFE, v3.1, 2014). SCHISM is an open-source community-supported modelling system designed for simulation of three-dimensional (3D) circulation across creek to ocean scale. SCHISM based on unstructured grids uses an accurate and highly efficient semi-implicit finite element method to solve the Navier-Stokes equations. And the time stepping has not constraints if the value of Courant-Friedrichs-Lewy (CFL) condition is satisfied between 0.4 and 1.0. The most important advantage of the SCHISM is its ability to use Message Passing Interface (MPI), which can simulate much faster than other models. SCHISM solves the Reynoldsaveraged Navier-Stokes equations for incompressible fluids under Boussinesq assumption. The governing equations of SCHISM are as presented from Eq. (1) to (4). And the generic length-scale model of Umlauf and Burchard (2003), $k-\varepsilon, k-k l$ and $k-\omega$ model are used with turbulence closure in SCHISM.

Continuity equation

$$
\frac{\partial \eta}{\partial t}+\nabla \cdot \int_{-h}^{\eta} u d z=0 \text { (2D form) }
$$

$$
\nabla \cdot u+\frac{\partial w}{\partial t}=0(3 \mathrm{D} \text { form })
$$

Momentum equation

$$
\frac{D u}{D t}=\frac{\partial}{\partial z}\left(v \frac{\partial u}{\partial z}\right)-g \nabla \eta+F .
$$

Transport equations

$$
\frac{\partial C}{\partial t}+\nabla \cdot(u C)=\frac{\partial}{\partial z}\left(\kappa \frac{\partial C}{\partial z}\right)+F_{h},
$$

where $z$ is the vertical coordinate (upward), $t$ is the time, $\eta$ is the free surface elevation, $h$ is the bathymetric depth, $u$ is the horizontal velocity, $w$ is the vertical velocity, $F$ is the other forcing terms in momentum such as horizontal viscosity, Coriolis, earth tidal potential and atmospheric pressure, $g$ is the acceleration of gravity, $C$ is the tracer concentration such as salinity, temperature, $v$ is the vertical eddy viscosity, $\kappa$ is the vertical eddy diffusivity for tracers, $F_{h}$ is the horizontal diffusion.

The additional information about SCHISM such as publications and manual to use model can be found on the SCHISM website: schism.wiki. And various applications of the SCHISM, for instance San Francisco Bay and Delta project performed by California Department of Water Resources (DWR) and Virginia Institute of Marine Sciences(VIMS) and examination of water quality project in the Chesapeake Bay Region conducted by VIMS and so on, ensure the accurate simulation about hydrodynamics and water quality, which is needed for the transport and diffusion of water quality variables (Wang et al., 2020).

\subsection{CoSiNE model}

The ecological simulations are performed by the Carbon, Silicate, Nitrogen Ecosystem (CoSiNE) model which is the one of the modules in SCHISM designed for modeling the ocean biogeochemical processes in the Pacific Ocean (Chai et al., 2002, 2003, 2007). The 13 state variables describing 2 zooplankton species, 2 phytoplankton species, 3 groups of nitrogen form, 2 groups of silicon form, 1 group of phosphorus form, total carbon dioxide, dissolved oxygen and total alkalinity are used in the CoSiNE model. Conceptual model equations of the CoSiNE can be expressed as follows.

$$
\frac{\partial C}{\partial t}=\operatorname{Physics}(C)+\operatorname{Biology}(C),
$$

where $C$ represents the one of 13 CoSiNE variables, Physics $(C)$ is the process of the physical source and sink and Biology $(C)$ is the process of the biological source and sink.

The physical process including advection and diffusion is calculated in SCHISM and the biological process including mass balance equation is calculated in CoSiNE model. The variables in CoSiNE model are listed in Table 1. 
Table 1. List of CoSiNE model variables

\begin{tabular}{|l|c|c|}
\hline \multicolumn{1}{|c|}{ Name of State Variables } & Symbol & Unit \\
\hline Nitrate & $\mathrm{NO}_{3}$ & $\mathrm{mmol} / \mathrm{m}^{3}$ \\
\hline Silicate & $\mathrm{SiO}_{4}$ & $\mathrm{mmol} / \mathrm{m}^{3}$ \\
\hline Ammonium & $\mathrm{NH}_{4}$ & $\mathrm{mmol} / \mathrm{m}^{3}$ \\
\hline Small Phytoplankton & $\mathrm{S} 1$ & $\mathrm{mmol} / \mathrm{m}^{3}$ \\
\hline Diatom & $\mathrm{S} 2$ & $\mathrm{mmol} / \mathrm{m}^{3}$ \\
\hline Microzooplankton & $\mathrm{Z} 1$ & $\mathrm{mmol} / \mathrm{m}^{3}$ \\
\hline Mesozooplankton & $\mathrm{Z} 2$ & $\mathrm{mmol} / \mathrm{m}^{3}$ \\
\hline Detritus Nitrogen & $\mathrm{DN}$ & $\mathrm{mmol} / \mathrm{m}^{3}$ \\
\hline Detritus Silicon & $\mathrm{DSi}$ & $\mathrm{mmol} / \mathrm{m}^{3}$ \\
\hline Phosphate & $\mathrm{PO}$ & $\mathrm{mmol} / \mathrm{m}^{3}$ \\
\hline Dissolved Oxygen & $\mathrm{DO}_{2}$ & $\mathrm{mmol} / \mathrm{m}^{3}$ \\
\hline Dioxide Carbon & $\mathrm{CO}_{2}$ & $\mathrm{mmol} / \mathrm{m}^{3}$ \\
\hline Alkalinity & $\mathrm{ALK}$ & $\mathrm{meq} / \mathrm{m}^{3}$ \\
\hline
\end{tabular}

\section{Case study}

Before analyzing the SCHISM-CoSiNE model results, both hydrodynamic and ecological modules were verified by comparing the results of simulation with analytical solution from previous study or measured data on Saemangeum basin. We first compared the velocity distribution at the section enlargement to verify the performance in hydrodynamic module in SCHISM. Then we verified the CoSiNE model's performance (i.e. temperature, salinity, dissolved oxygen, and concentration of nitrate and phosphate) in response to consider the drainage gate operation under specific assumptions as a inner boundary condition.

\subsection{Case 1: Hydrodynamic module}

Wang (1984) presented the analytical solution for the velocity distribution in the section enlargement under steady state conditions. The topography of the section enlargement was represented by idealized channel (see Figure 1).

For convenience and generalization, he normalized the all variables. And the velocity distribution was expressed to be non-dimensional for $x_{1}$ and $x_{2}$ axes as follows.

$$
u(r, s)=u_{0}\left(1-s^{2}\right) \exp \left(-s^{2}\right) U(r)
$$

\section{a) Analytical solution}

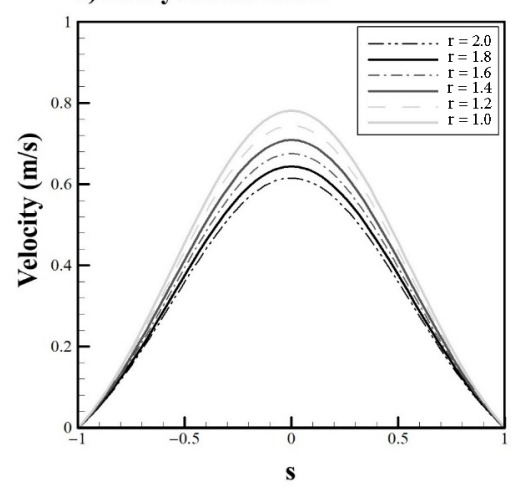

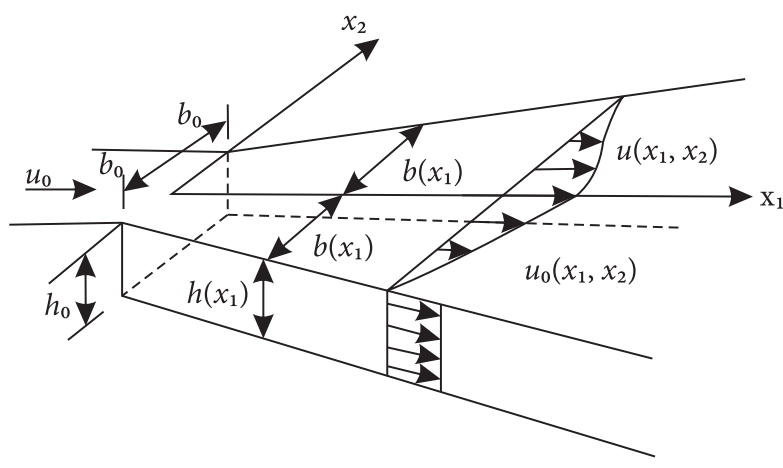

Figure 1. Schematic diagram of Channel (Wang, 1984); where, $b_{0}$ is the half of initial width at section enlargement, $h_{0}$ is the initial depth at section enlargement, $u_{0}$ is the initial velocity

$$
U(r)=\left(h / h_{0}\right)^{-\frac{f}{a}},
$$

where $u(r, s)$ is the velocity at $(r, s), r$ is the normalized longitudinal distance defined as $x_{1} / b_{0}, s$ is the normalized lateral distance defined as $x_{2} / b, a$ is the bottom slope of channel, and $f$ is the friction coefficient.

The initial conditions are listed in Table 2 and the simulations are performed after representing the idealized channel with the SCHISM. The results of SCHISM and the analytical solutions are compared for velocity distribution ranging from 1.0 to 2.0 for $r$ according to $s$ (see Figure 2).

Table 2. Initial conditions

\begin{tabular}{|c|c|}
\hline Variables & Value \\
\hline$b_{0}$ & $500 \mathrm{~m}$ \\
\hline$h_{0}$ & $2 \mathrm{~m}$ \\
\hline$u_{0}$ & $1 \mathrm{~m} / \mathrm{s}$ \\
\hline$f$ & 0.001 \\
\hline$a$ & 0.0001 \\
\hline
\end{tabular}

When the velocity distribution is compared at the center of the channel $(s=0)$, the error between the analytical solution and the computational results of SCHISM becomes within $1.6 \%$. Thus, the SCHISM is expected to

b) SCHISM results

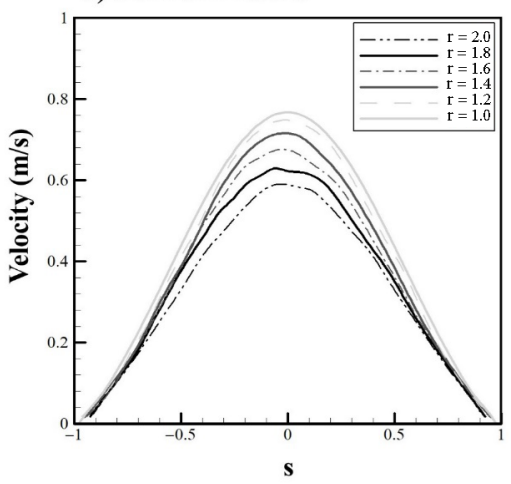

Figure 2. a) Velocity distribution of Analytical Solution, b) Velocity distribution of SCHISM results 
show well performance with a high accuracy to simulate enlargement flow like estuaries. The errors between SCHISM and analytical solution according to are listed in Table 3.

Table 3. Error of velocity comparison at centreline $(s=0)$ between analytical solution and SCHISM results

\begin{tabular}{|c|c|c|c|}
\hline$r$ & $\begin{array}{c}\text { Analytical } \\
\text { Solution }(\mathrm{m} / \mathrm{s})\end{array}$ & $\begin{array}{c}\text { SCHISM } \\
(\mathrm{m} / \mathrm{s})\end{array}$ & Error (\%) \\
\hline 1.0 & 0.78 & 0.77 & 1.28 \\
\hline 1.2 & 0.74 & 0.75 & 1.35 \\
\hline 1.4 & 0.71 & 0.71 & 0.00 \\
\hline 1.6 & 0.68 & 0.68 & 0.00 \\
\hline 1.8 & 0.64 & 0.63 & 1.56 \\
\hline 2.0 & 0.61 & 0.60 & 1.64 \\
\hline
\end{tabular}

\subsection{Case 2: Ecological module}

In Saemangeum basin, there are two drainage gates called as the Sinsi (10 gates) and the Garyeok (8 gates) drainage gates which are located at M15 and D15 in Figure 3, respectively. And the drainage gate operation with seawater circulation was performed to maintain the water quality. Since the reproduction of the seawater circulation is necessary for the verification of the CoSiNE model, the seawater circulation is indirectly reproduced by considering operation time log of gates, the tide data around the drainage gate and the designated water surface elevation. The following assumptions are required to reproduce the operation of the drainage gates (Jeong et al., 2018a; Ryu, 2018):

1) The opening of the drainage gate takes precedence over the maintenance of the water surface elevation.

2) The operation time of the drainage gate is constantly 4 hours on average.

3) The drainage gate opens 16 times a month and the time required to open and close the gate is 1 hour on average.

4) The discharge of input and output through the drainage gate changes linearly with time.

5) The discharge from the inside of the lake through the drainage gate to the offshore is the same as the discharge of upstream.

So, the operation of the Sinsi and Garyeok drainage gates based on the above assumptions is set as follows (see Figure 4).

The study area is determined to be from the Mangyeong Bridge and the Dongjin Bridge, where the measured data exists, up to the Saemangeum sea dike that reaches the Sinsi and Garyeok drainage gates. The upstream boundary conditions are set at the discharge of July 2016

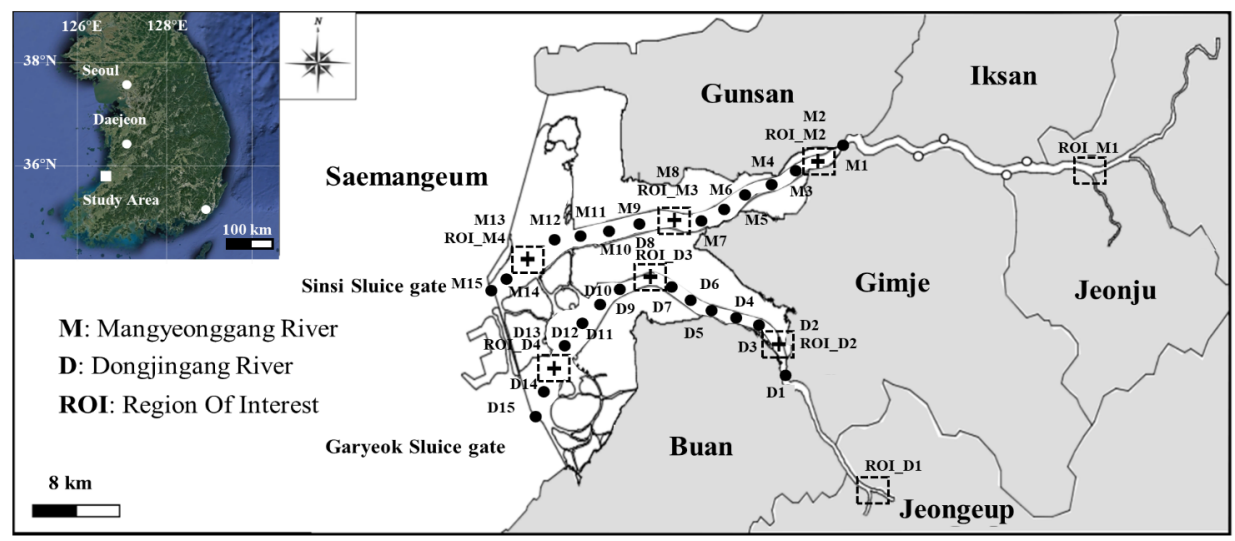

Figure 3. Comparison points between the SCHISM-CoSiNE model and the field measured data

("black o mark": SCHISM-CoSiNE model results from Dongjingang River to Garyeok drainage gate and from Mangyeonggang River to Sinsi drainage gate, "black + mark": field measured data by

Korean Rural Community Corporation) and regions of interest (“black dashed rectangular mark”: region of interest)
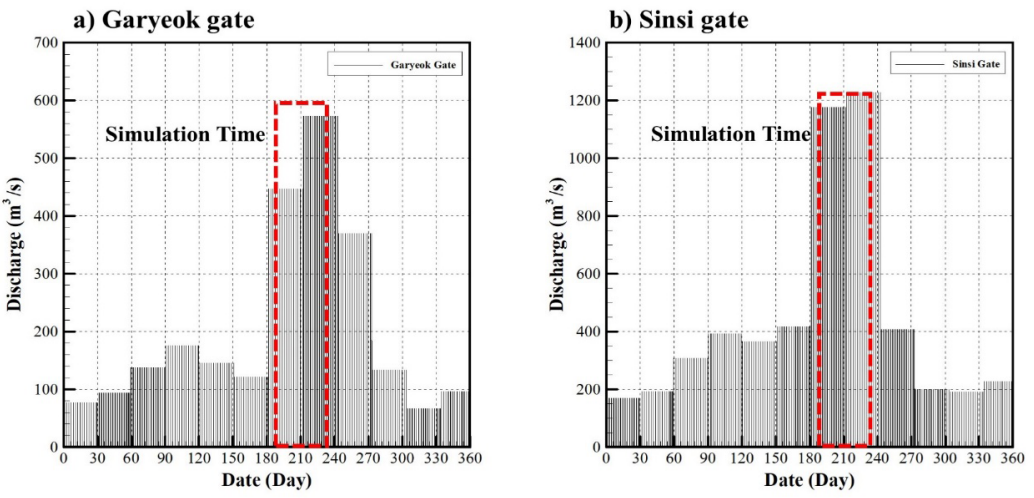

Figure 4. a) The operation of Garyeok gate, b) The operation of Sinsi gate 
using the Water Resources Management Information System (WAMIS, Korea) data. The measured data about water quality in Saemangeum basin (Korea Rural Community Corporation, 2016) is used to verify the CoSiNE model. Since the measured data is presented monthly, the constant pollutant concentration is set in the corresponding month. And the 5 variables such as temperature, salinity, nitrate concentration, phosphate concentration, dissolved oxygen concentration are used only in this study. The section marked " + " is the point where the water quality data is measured, and the section marked " $\mathrm{o}$ " is the point where the results of the simulation with CoSiNE model (see Figure 3). The total elements are 51,364 and total nodes are 31,730 with quad and triangular grids in SCHIM-CoSiNE model. Target simulation period is one month from June 15, 2016 to July 15, 2016. The numerical conditions are listed in Table 4.

Table 4. The numerical conditions for verifying the ecological module

\begin{tabular}{|l|l|l|}
\hline Parameter & \multicolumn{1}{|c|}{ Variable } & \multicolumn{1}{c|}{ Value } \\
\hline $\begin{array}{l}\text { Grid } \\
\text { spacing }\end{array}$ & $\Delta x, \Delta y, \Delta z$ & $\begin{array}{l}20 \mathrm{~m} \text { in River } \\
60 \mathrm{~m} \text { in Estuary } \\
3 \text { vertical level }\end{array}$ \\
\hline Time step & $d t$ & $10 \mathrm{sec}$ \\
\hline $\begin{array}{l}\text { Turbulence } \\
\text { model }\end{array}$ & - & $k-\varepsilon$ model \\
\hline \multirow{2}{*}{$\begin{array}{l}\text { Boundary } \\
\text { Condition }\end{array}$} & Mangyeong & Discharge: time series \\
\cline { 2 - 4 } & Dongjin & Discharge: time series \\
\cline { 2 - 4 } & Garyeok gate & Water surface elevation: constant \\
\hline
\end{tabular}

The results of SCHISM-CoSiNE simulation about discharge of inflow and outflow through the drainage gates are compared with measured data (see Figure 5). The error of peak discharge is the $1.5 \%$ and the error of discharge within one month is about $5.0 \%$. So, the SCHISM-CoSiNE

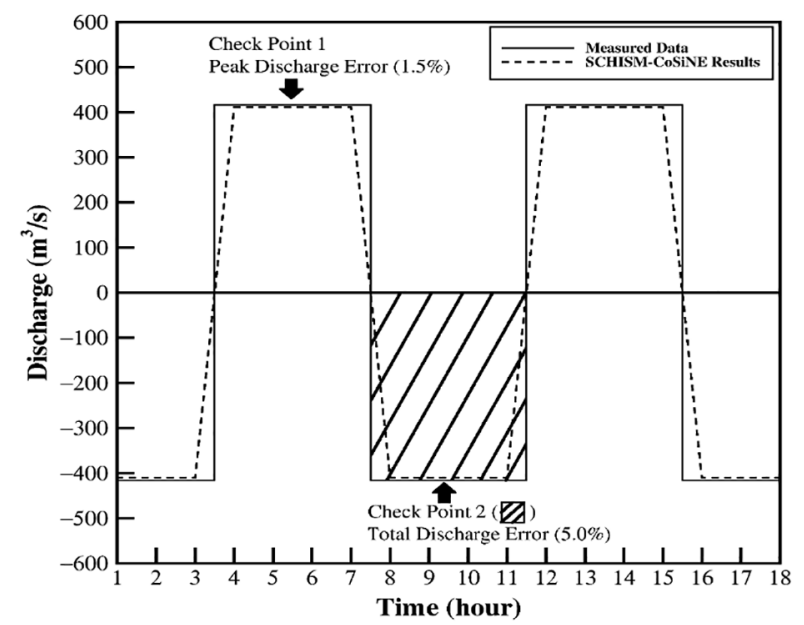

Figure 5. Comparisons of SCHISM-CoSiNE results and measured data about discharge of input and output through drainage gate model is well simulated for the operation of drainage gates. And, it is confirmed that the value of each coefficient such as contraction in outflow direction and expansion in inflow direction ranged from 0.98 to 1.00 for near the drainage gates by the velocity vector fields in the results of SCHISM-CoSiNE. Also, the results of modelling about water quality, temperature and salinity are compared with the measured data at the measuring points as mentioned above (see Figure 6). It is confirmed that the results of numerical simulations and measured data are well matched at most measuring points. The errors between numerical simulation and measured data are listed in Table 5.

For each variable, the SCHISM-CoSiNE simulation results compared with the measured data showed the relative error within $7.00 \%$. Especially, the concentration of nitrate was compared with the numerical simulation results using the Delft3D model (Jeong et al., 2018a). The simulations performed by each numerical model have same spec of Computer, Intel Xeon E5-2650 (24 core) and 64 GB Random Access Memory (RAM), and numerical conditions such as time step, number of elements. The result of each model at measuring points was compared with measrued data and showed that the relative error was within 10.0\% in SCHISM-CoSiNE and 20.0\% in Delft3D model (see Figure 7). From these results, it was confirmed that the performance of SCHISM-CoSiNE model was better than the Delft3D model in terms of accuracy. Also, the computing time for simulation using SCHISM-CoSiNE model was up to six times faster than Delft3D model due to the use of MPI in SCHISM-CoSiNE.

Table 5. Relative error at measuring points

\begin{tabular}{|c|c|c|c|c|c|}
\hline \multicolumn{2}{|c|}{ Variable } & $\begin{array}{c}\mathrm{T}^{*} \\
(\%)\end{array}$ & $\begin{array}{c}\mathrm{S}^{* *} \\
(\%)\end{array}$ & $\begin{array}{c}\mathrm{PO}_{4} \\
(\%)\end{array}$ & $\begin{array}{c}\mathrm{D} \\
(\%)\end{array}$ \\
\hline \multirow{4}{*}{ Point } & $\mathrm{M} 2$ & 0.07 & 0.00 & 0.72 & 0.14 \\
\cline { 2 - 6 } & $\mathrm{M} 8$ & 0.07 & 4.17 & 3.49 & 0.56 \\
\cline { 2 - 6 } & $\mathrm{M} 13$ & 0.00 & 0.39 & 6.85 & 1.45 \\
\cline { 2 - 6 } & $\mathrm{D} 2$ & 0.07 & 0.00 & 0.78 & 0.80 \\
\cline { 2 - 6 } & $\mathrm{D} 8$ & 0.04 & 2.17 & 3.85 & 0.99 \\
\cline { 2 - 6 } & $\mathrm{D} 13$ & 0.00 & 1.58 & 2.86 & 0.76 \\
\hline
\end{tabular}

Note: ${ }^{\star} \mathrm{T}-$ Temperature. ${ }^{\star} \mathrm{S}-$ Salinity.

\section{Scenario configuration}

The objective of this study is to examine the quantatively changes of water quality caused by the variations of hydraulic characteristics due to the Saemangeum basin Master Plan (Korean Government, 2011) considering the drainage gate operation. We assumed all environments were set up in the future, especially in 2030 when all constructions will be completed according to the Saemangeum basin Master Plan, and the simulation was performed from June to August corresponding to the flood season. The saltwater inflows through drainage gates will not be occurred and only the outflow from the inner lake to the sea will be considered because the major objective of 
(a) Water quality characteristics in Mangyeonggang River
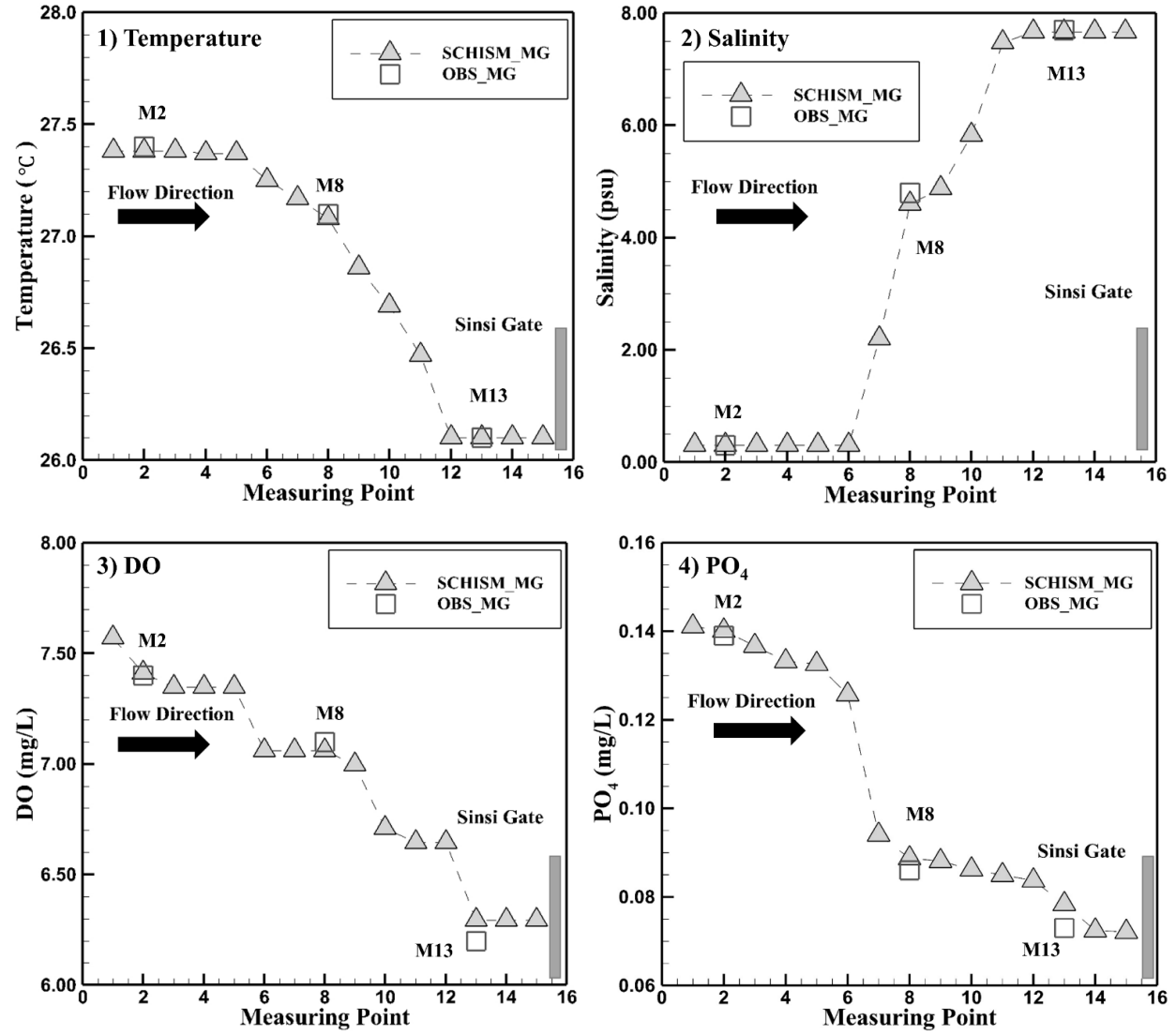

(b) Water quality characteristics in Dongjingang River
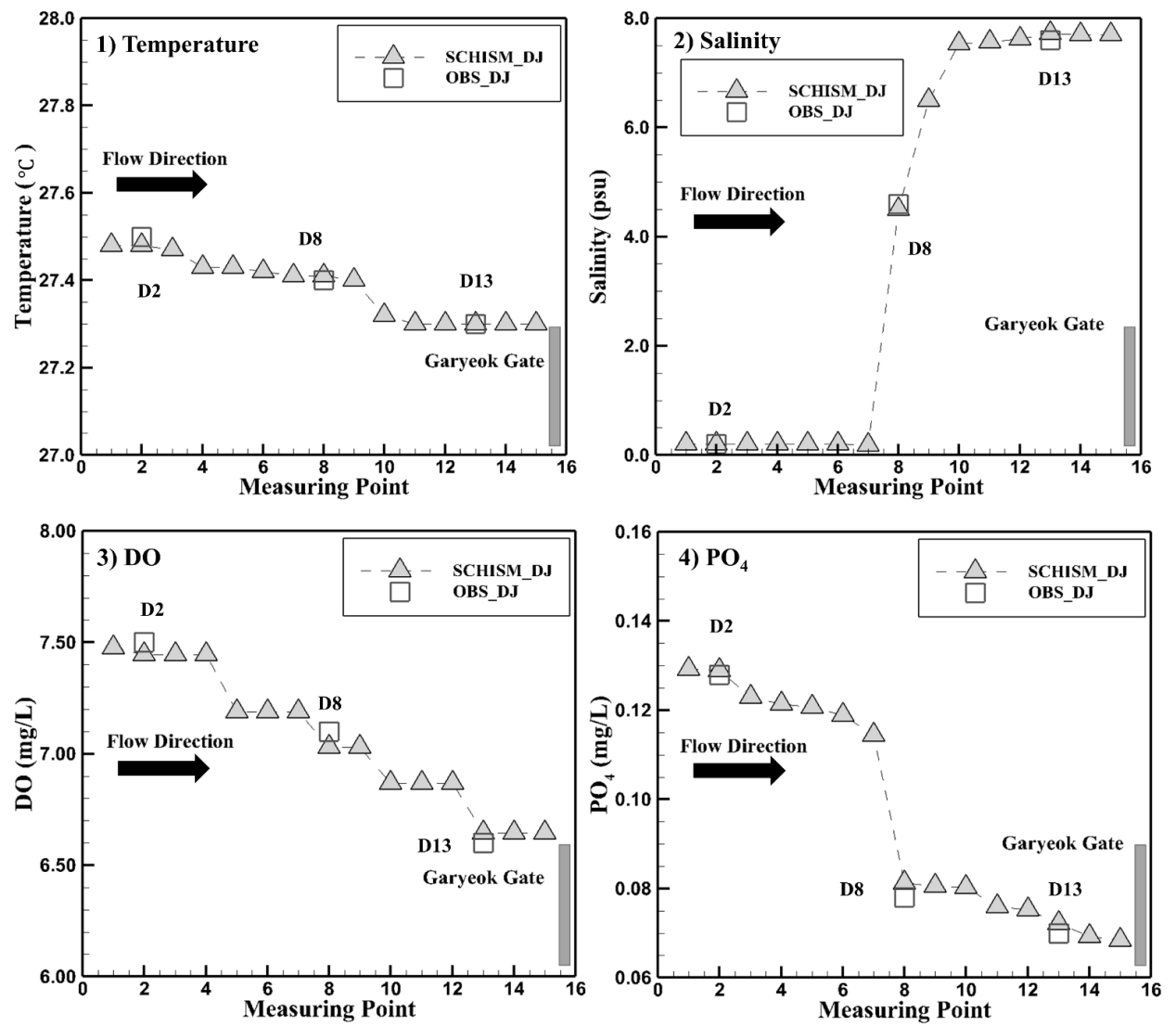

Figure 6. Comparison of SCHISM-CoSiNE results and measured data about

1) temperature, 2) salinity, 3) concentration of dissolved oxygen, 4) concentration of phosphate 

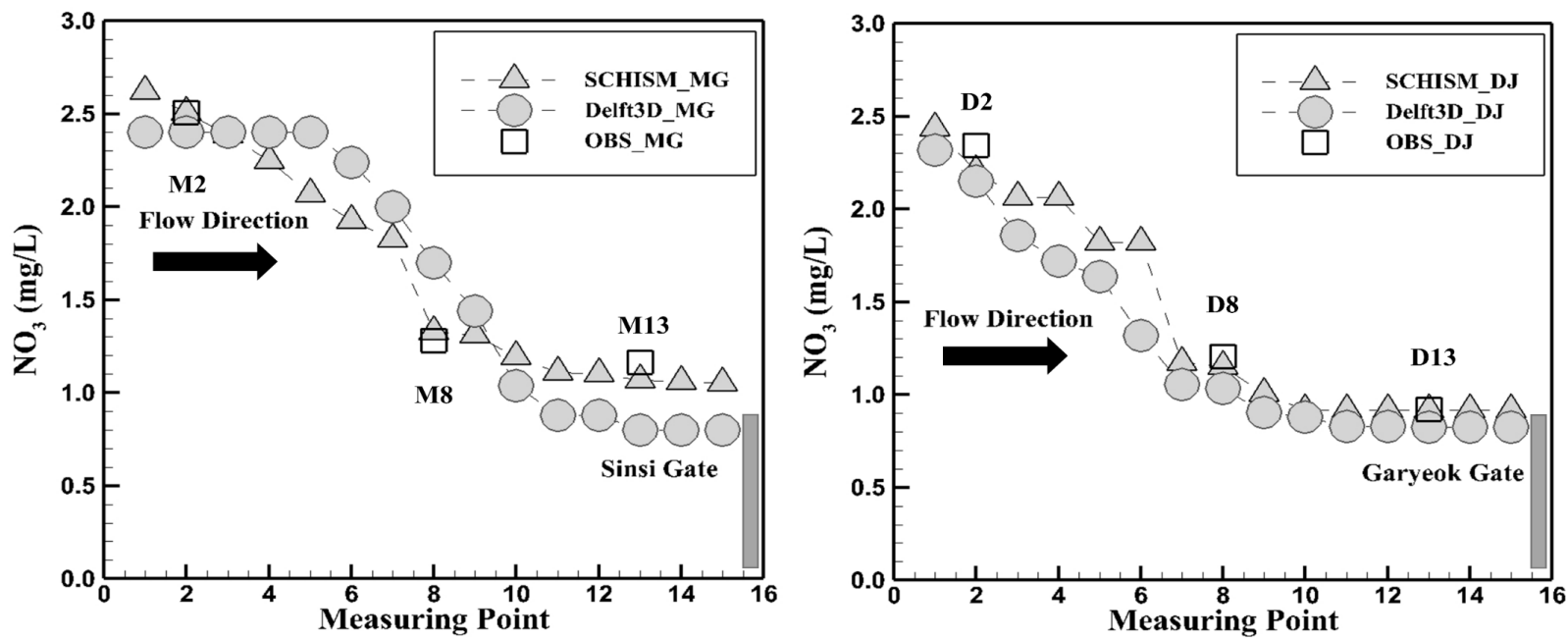

Figure 7. Comparison on the result of SCHISM-CoSiNE and Delft3D in terms of concentration about nitrate at measuring points

Saemangeum basin Master Plan is the desalination in lake. And, the abundant water supply is the one of the objectives in Master Plan in Saemangeum basin. The operation of the drainage gates was based on the assumptions previously mentioned (Jeong et al., 2018a; Ryu, 2018) and the specific condtions was considered in this study. Since the problem defined in Saemangeum basin was complicated to forecast the climate variability in the future, the average discharge obtained from WAMIS for recent 10 years was set as upstream boundary conditions. In addition, the tributary discharges to Mangyeonggang River and Dongjingang River were relatively similar value compared with main channel flow in Saemangeum basin. The drainage-area ratio method was used to calculate the tributary discharges for sites where no discharge data were available using data from one or more nearby stations. The scenarios for the numerical analysis are summarized according to the designated water surface elevation in Table 6.

Table 6. Scenarios for the numerical simulation

\begin{tabular}{|c|c|}
\hline Scenario & $\begin{array}{c}\text { Designated Water Surface Elevation } \\
\text { of Drainage gates (EL. m) }\end{array}$ \\
\hline 1 & -1.7 \\
\hline 2 & -1.6 \\
\hline 3 & -1.5 \\
\hline 4 & -1.4 \\
\hline 5 & -1.3 \\
\hline
\end{tabular}

The total elements are 21,064 and total nodes are 15,730 with quad and triangular grids in SCHIM-CoSiNE model. The CFL number is the range from 0.6 in estuary to 0.9 in river. The numerical conditions are listed in Table 7.

Five variables such as temperature, salinity, $\mathrm{NO}_{3}$ concentration, $\mathrm{PO}_{4}$ concentration and dissolved oxygen concentration are used in SCHISM-CoSiNE model. The value of each variable in Saemangeum basin was confirmed by remaining constant through the analysis of measured
Table 7. The numerical conditions

\begin{tabular}{|l|l|l|}
\hline \multicolumn{1}{|c|}{ Parameter } & \multicolumn{1}{|c|}{ Variable } & \multicolumn{1}{c|}{ Value } \\
\hline $\begin{array}{l}\text { Grid } \\
\text { spacing }\end{array}$ & $\Delta x, \Delta y, \Delta z$ & $\begin{array}{l}40 \mathrm{~m} \text { in River } \\
200 \mathrm{~m} \text { in Estuary } \\
5 \text { vertical level }\end{array}$ \\
\hline Time step & $d t$ & $20 \mathrm{sec}$ \\
\hline $\begin{array}{l}\text { Turbulence } \\
\text { model }\end{array}$ & - & $k-\varepsilon$ model \\
\hline $\begin{array}{l}\text { Boundary } \\
\text { Condition }\end{array}$ & Mangyeong & Discharge: time series \\
\cline { 2 - 3 } & Dongjin & Discharge: time series \\
\cline { 2 - 4 } & Sinsi gate & $\begin{array}{l}\text { Water Surface elevation: } \\
\text { scenario }\end{array}$ \\
\cline { 2 - 3 } & Garyeok gate & $\begin{array}{l}\text { Water Surface elevation: } \\
\text { scenario }\end{array}$ \\
\hline
\end{tabular}

data for 5 years (Korean Rural Community Corporation, 2012 2015, 2016). In addition, the Mangyeonggang River and Dongjingang River were planned to construct sedimentation facilities, phosphorus treatment facilities and sewage disposal facilities to the Mangyeong Bridge and Dongjin Bridge respectively in the Saemangeum Master Plan. However, the eco-friendly plan was not applied up to the upstream. It was judged that each amount of inlet pollutants into Mangyeonggang River and Dongjingang River was similar to those at the present time. The input data was, therefore, constructed employing the recent field measurement data. Since the measured data in Saemangeum basin was provided only once a month and the record time was not precisely known, it was assumed that the measurements were performed on the first day of each month, and the inflow conditions between month and month were linearly interpolated.

\section{Results and discussion}

The results of SCHISM-CoSiNE model for hydraulic characteristics and water quality with change of the designated water surface elevation are reviewed in the regions 
of interest (see. Figure 3). The section 1 such as ROI-M1 and ROI-D1 is the junction area in the upstream of Mangyeong River and Dongjin River, respectively. The section 2 including ROI-M2 and ROI-D2 is the dredged section for removing the contaminants in the lake. The section 3 containing ROI-M3 and ROI-D3 is the middle point of the Saemangeum inner lake. And the section 4 involving ROI-M4 and ROI-D4 is around the drainage gates.

First, the hydraulic results of SCHISM-CoSiNE model are analyzed against the designated water surface elevations. It shows a negative correlation with the Pearson correlation coefficient of -0.90 between the designated water surface elevations and ratio of discharge $\left(Q_{o u t} / Q_{\text {in }}\right)$. On the other hand, the positive correlation with the Pearson correlation coefficient of 0.96 was shown between the designated water surface elevations and ratio of water volume $\left(V / V_{s}\right)$ as above in Figure $\left.8 \mathrm{a}\right)$ and b), respectively.

It is because the inlet discharge $\left(Q_{i n}\right)$ is the constant by the boundary condition. However, the outlet discharge $\left(Q_{\text {out }}\right)$ from inner lake to sea through the drainage gates is reduced becasue of decreasing the frequency of gate opening to maintain the water surface elevation in Saemangeum basin. So, the water volume is increased as water surface elevation increasing. These results are similar to those found in the previous researches (Jeong et al., 2018a; Li \& Kim, 2019; Oda et al., 2019).

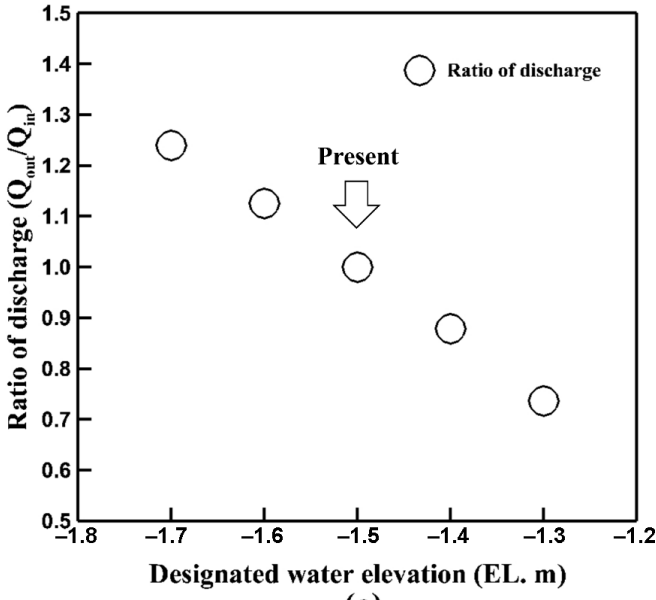

(a)

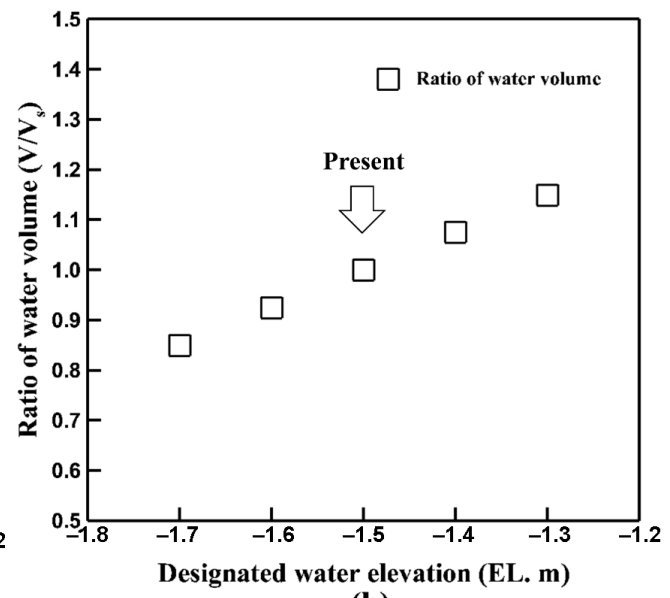

(b)

Figure 8. a) Ratio of discharge according to designated water surface elevation,

b) Ratio of water volume according to designated water surface elevation $\left(Q_{\text {in }}=\right.$ inlet discharge when designated water surface elevation value is EL. $-1.5 \mathrm{~m}$, = water volume when designated water surface elevation value is EL. $-1.5 \mathrm{~m}$ )

(a) Changes of water quality characteristics with designated water elevation in Mangyeonggang river
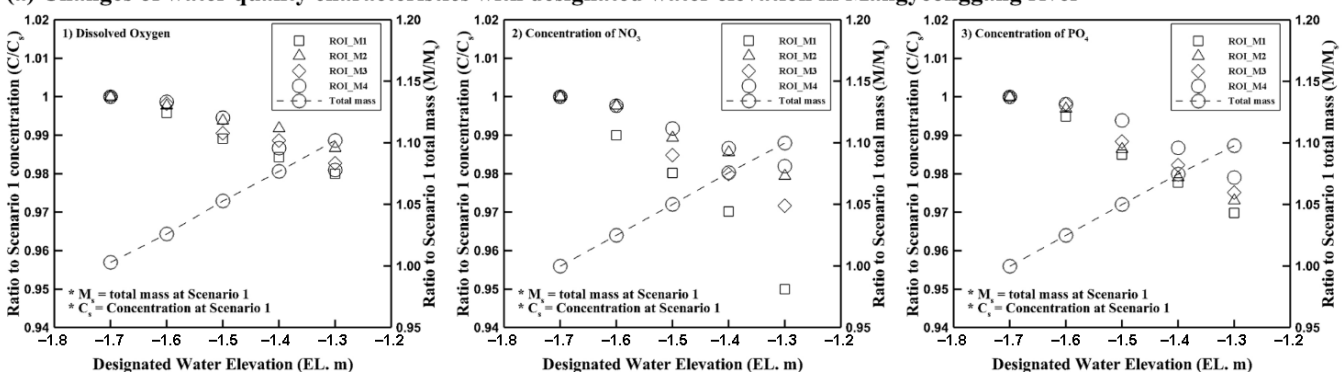

(b) Changes of water quality characteristics with designated water elevation in Dongjingang river
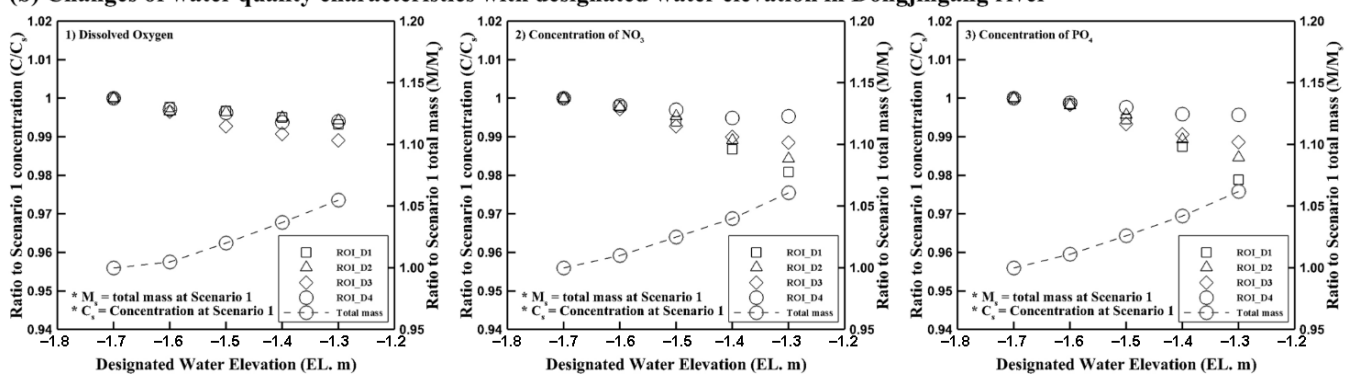

Figure 9. a) Ratio to scenario 1 concentration $\left(C / C_{s}\right)$ and total mass $\left(M / M_{s}\right)$ about dissolved oxygen according to designated water surface elevation, b) Ratio to scenario 1 concentration $\left(\mathrm{C} / \mathrm{C}_{\mathrm{s}}\right)$ and total mass $\left(\mathrm{M} / \mathrm{M}_{\mathrm{s}}\right)$ about $\mathrm{NO}_{3}$ according to designated water surface elevation, $c)$ Ratio to scenario 1 concentration $\left(C / C_{s}\right)$ and total mass $\left(M / M_{s}\right)$ about $P_{4}$ according to designated water surface elevation $\left(\mathrm{C}_{\mathrm{s}}=\right.$ Concentration at Scenario $1, \mathrm{M}_{\mathrm{s}}=$ total mass at scenario 1$)$ 
Second, the water quality results from SCHISMCoSiNE model including dissolved oxygen (DO), concentration of nitrate $\left(\mathrm{NO}_{3}\right)$ and concentration of phosphate $\left(\mathrm{PO}_{4}\right)$ are analyzed as the designated water surface elevations are varied at each regions of interest (see Figure 9). The water quality characteristics are consistent with the previous findings (Minh et al., 2019; Oda et al., 2019) such that the change in concentration of dissolved oxygen $(\mathrm{DO})$, nitrate $\left(\mathrm{NO}_{3}\right)$, and phosphate $\left(\mathrm{PO}_{4}\right)$ is highly dependent on water volume change. It is also reviewed by the adevection-diffusion equation that the concentration is inversely proportional to the crosssectional area and velocity (Mirza \& Vieru, 2017). The change of velocity is effective to change the concentration of materials in upstream Mangyeonggang river and Dongjingang river. However, after the dredged section where the water depth is deepened, the concentration of materials sharply decreases and maintains less varying in the inner lake section (see Figure 10). From

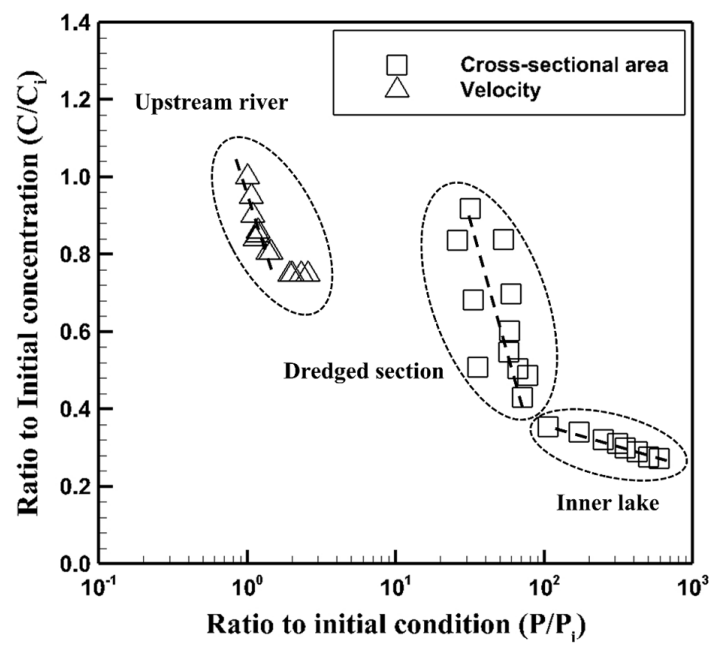

Figure 10. The sensitivity analysis in the change of concentration with cross-sectional area and velocity change

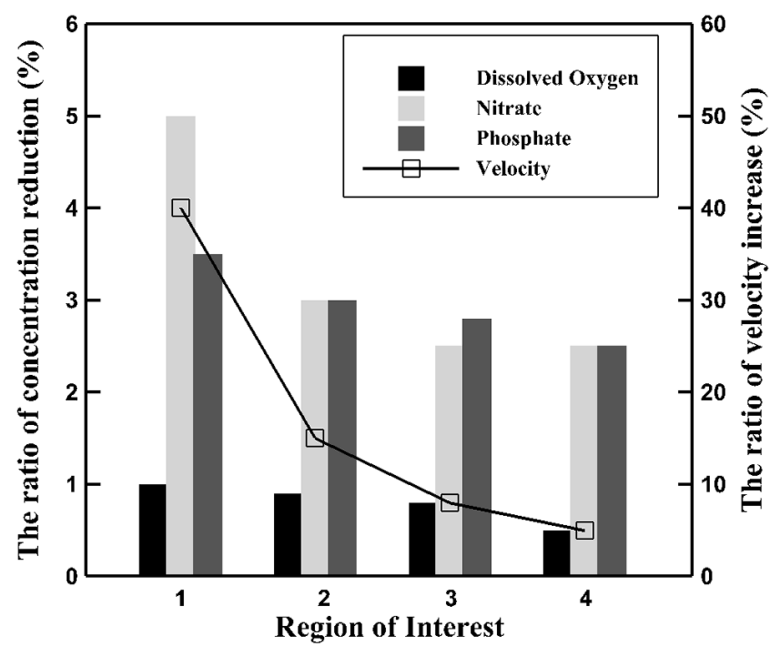

Figure 11. Ratio of concentration reduction and the ratio of velocity decrease at regions of interest when the designated water surface elevation increase these results, it can be concluded that the change of cross-sectional area is the dominant factors to control the concentration of water quality variables. When the water volume in the basin is increased as a result of incresed designated water elelvations, concentrations of the chemical materials are reduced since the volume of solution increases while the mass increased due to residual materials in the basin and chemical reaction on materials. For example, In case of the dissolved oxygen, its concentration is affected by the temperature, salinity, water depth and other water attributes. The concentration is reduced as the temperature increases, the salinity increases, and the water depth increases (Manasrah et al., 2006; Jeong et al., 2018a). The modelling results show that temperature decreases toward to downstream and salinity increases due to saltwater intrusion. At the same time, the water depth is deepened by dredged bottom level (ROI_M3 and ROI_D3). These are consistent to expected outcomes. In case of the nitrate, the change of concentration process is similar as the process of dissolved oxygen. However, the concentration of nitrate becomes almost constant in the inner lake despite of the increase of water depth. This is because the nitrification reaction is occurred in this area, where the range of hydrogen ion concentration exponent $(\mathrm{pH})$ is 7.5 to 8.0 and the concentration of dissolved oxygen is 6.0 to $7.0 \mathrm{mg} / \mathrm{l}$ satisfied the best environment of nitrification reaction (Lenton \& Watson, 2000). From this reaction in the inner lake, the mass of nitrate slightly increases. And the residual nitrate, which does not flow out through the drainage gate, prevents a sharply decrease in concentration. The concentration of phosphate shows a similar behavior to the concentration of nitrate, which is comparable with the finding of previous research (Quirós, 2003).

It is summarized changes of velocity and other water quality variables at each regions of interest in Figure 11. The concentration of the all variables at the regions of interest decreases when the designated water surface elevation increases. Also, the velocity decreases at the all sections because water depth increases at the same inlet discharge.

Finally, the water quality evaluation of Saemangeum basin was performed by using the simulation results according to the designated water surface elevation. The water quality standards (Environment Policy Basic Law, article 10, Ministry of Environment, Korea) are used to evaluate the grade of water quality in Saemangeum basin and listed in Table 8 .

If the ratio of total nitrate concentration to total phosphate concentration (T-N/T-P) is under 7.0, the only T-N standard is used in the inner lake (Environment Policy Basic Law, article 10, Ministry of Environment, Korea) in Korea. From the ratio of total nitrate concentration to total phosphate concentration calculated by the simulation results (approximately between 2 to 5), the only T-N standard is used in this study (see Figure 12). 
Table 8. Water quality standards in Saemangeum basin

\begin{tabular}{|c|c|c|c|c|c|c|}
\hline Grade & \multicolumn{2}{|c|}{$\begin{array}{c}\text { Do } \\
(\mathrm{mg} / \mathrm{L})\end{array}$} & \multicolumn{2}{|c|}{$\begin{array}{c}\text { T-P } \\
(\mathrm{mg} / \mathrm{L})\end{array}$} & \multicolumn{2}{|c|}{$\begin{array}{c}\mathrm{T}-\mathrm{N} \\
(\mathrm{mg} / \mathrm{L})\end{array}$} \\
\hline \multirow{2}{*}{$\begin{array}{l}\text { I } \\
\text { (Excellent) }\end{array}$} & $a^{*}$ & $b^{* *}$ & a & $b$ & $\mathrm{a}$ & $\mathrm{b}$ \\
\hline & \multicolumn{2}{|c|}{$\geq 7.00$} & $\leq 0.01$ & $\leq 0.04$ & \multicolumn{2}{|c|}{$\leq 0.20$} \\
\hline \multirow{2}{*}{$\begin{array}{l}\text { II } \\
\text { (Good) }\end{array}$} & $\mathrm{a}$ & b & a & b & $\mathrm{a}$ & b \\
\hline & \multicolumn{2}{|c|}{$\geq 5.00$} & $\leq 0.03$ & $\leq 0.10$ & \multicolumn{2}{|c|}{$\leq 0.40$} \\
\hline \multirow{2}{*}{$\begin{array}{l}\text { III } \\
\text { (Medium) }\end{array}$} & $\mathrm{a}$ & b & a & $\mathrm{b}$ & $\mathrm{a}$ & b \\
\hline & \multicolumn{2}{|c|}{$\geq 5.00$} & $\leq 0.06$ & $\leq 0.20$ & \multicolumn{2}{|c|}{$\leq 0.60$} \\
\hline \multirow{2}{*}{$\begin{array}{l}\text { IV } \\
\text { (Poor) }\end{array}$} & $\mathrm{a}$ & $\mathrm{b}$ & $\mathrm{a}$ & b & a & $\mathrm{b}$ \\
\hline & \multicolumn{2}{|c|}{$\geq 2.00$} & $\leq 0.15$ & $\leq 0.50$ & \multicolumn{2}{|c|}{$\leq 1.50$} \\
\hline \multirow{2}{*}{$\begin{array}{l}\mathrm{V} \\
\text { (Very poor) }\end{array}$} & $\mathrm{a}$ & b & $\mathrm{a}$ & b & $\mathrm{a}$ & b \\
\hline & \multicolumn{2}{|c|}{$<7.00$} & $>0.15$ & $>0.15$ & \multicolumn{2}{|c|}{$>1.50$} \\
\hline
\end{tabular}

Note: ${ }^{\star} \mathrm{a}$ - Inner lake. ${ }^{* *} \mathrm{~b}-$ River.

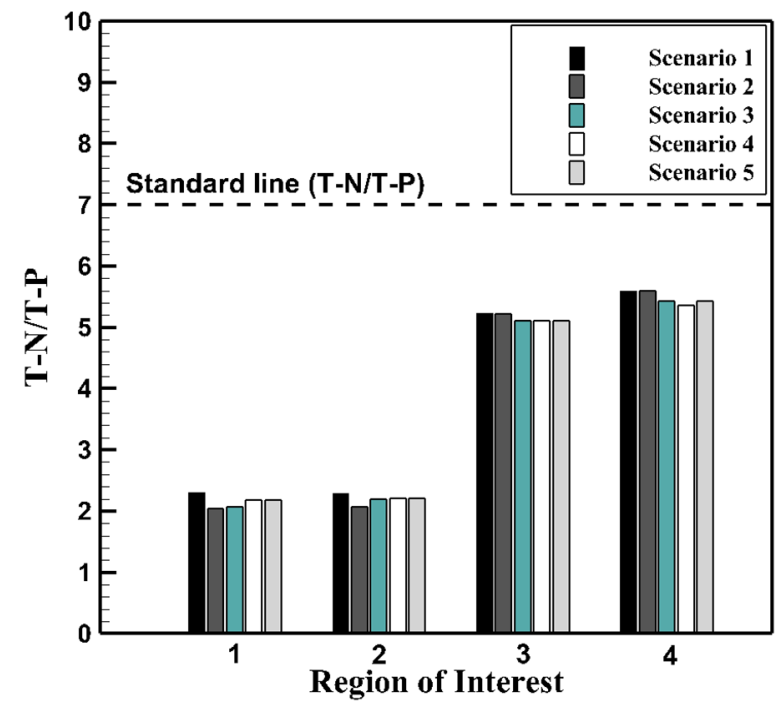

Figure 12. Ratio of total nitrogen to total phosphorus at the regions of interest (dash line is the standards to use the only T-N standards)

Table 9. Evaluation of water quality at ROI according to designated water surface elevation

\begin{tabular}{|c|c|c|c|c|c|c|}
\hline \multicolumn{3}{|c|}{ ROI } & 1 & 2 & 3 & 4 \\
\hline \multirow{10}{*}{ Grade } & \multirow{2}{*}{$-1.7 \mathrm{~m}$} & M & II & II & II & III \\
\hline & & D & II & II & III & III \\
\hline & \multirow{2}{*}{$-1.6 \mathrm{~m}$} & M & II & II & II & III \\
\hline & & $\mathrm{D}$ & II & II & III & III \\
\hline & \multirow{2}{*}{$-1.5 \mathrm{~m}$} & M & II & II & II & III \\
\hline & & $\mathrm{D}$ & II & II & III & III \\
\hline & \multirow{2}{*}{$-1.4 \mathrm{~m}$} & $\mathrm{M}$ & II & II & II & III \\
\hline & & $\mathrm{D}$ & I & II & III & III \\
\hline & \multirow{2}{*}{$-1.3 \mathrm{~m}$} & $\mathrm{M}$ & I & II & II & II \\
\hline & & $\mathrm{D}$ & I & II & III & III \\
\hline
\end{tabular}

The evaluation of water quality using T-N standard is summarized in Table 9. It is confirmed that the designated water surface elevation affected the water quality. Even though the total mass of variables such as nitrate and phosphate has increased when the designated water surface elevation increases, the increase of designated water surface elevation improves the water quality in Saemangeum basin. It also enhances the ability of water supply in Saemangeum basin and expects to be satisfied the needs of water supply from the Saemangeum basin Master Plan because of the increased water volume.

\section{Conclusions}

The numerical modelling was undertakened to review the water quality issues in the Saemangeum basin, Korea and to examine potential management actions to alleviate the issues. Because there was a brackish water in the Saemangeum basin, salt water flowed into the lake through the operation of drainage gate, it may be possible to find the most suitable mangement options of operating drainage gates to optimise the hydraulic and ecological changes.

This study applied the SCHISM-CoSiNE model to simulate the operation of drainage gate under specific assumptions. The model was used to invesitgate the changes of water quality with various designated water surface elevation conditions. The water quality variables in SCHISMCoSiNE model, the concentration of dissolved oxygen, nitrate and phosphate, were analyzed to evaluate the effect in change of designated water surface elevation as an optimal solution for water quality problem in the Saemangeum basin. From this study, some remarkable conclusions are drawn as follows:

1. SCHISM-CoSiNE model is well suited for simulation at inner lake where has hydraulic characteristics like brackish water because it reflects well operation of drainage gates conditions.

2. Compared with the measured data in the previous studies, the SCHISM-CoSiNE model can accurately and promptly simulate the water quality simulation.

3. As the designated water surface elevation increases, the operation of drainage gates can be one of the solutions to water quality problems through the result of improved water quality.

4. Not only in terms of water quality, but also in terms of water supply, an increase of designated water surface elevation has positive effect because the freshwater volume in lake increased.

Therefore, this study will suggest the useful information to derive an efficient management plan through examining in detail the changes of water quality according to various operation conditions in the Saemangeum basin Master Plan. However, circumspection is requested because the total mass of variables such as nitrate and phosphate have simultaneously increased when the designated water surface elevation has increased.

This study shows that the coupled SCHISM-CoSiNE model becomes a potential regulatory model to evaluate 
the water quality in Saemangeum basin based on the results in this study. Moreover, further improvements may be useful to enhance its applicability considering more dynamic operations of the designated water surface elevations to take into account typical Korean seasonal effect and other organic matters except ones included in this study.

\section{Acknowledgements}

This research was supported by Basic Science Research Program through the National Research Foundation of Korea (NRF) funded by the Ministry of Science, ICT \& Future Planning (No.2021R1A2C2013158).

\section{References}

Bae, Y. H., Yoon, B. I., Seo, C. H., Park, S. J., Bang, K. Y., Kwon, H. K., \& Woo. S. B. (2017). Residence time variation by operation of Sihwa Tidal Power Plant in Outer Sea of Sihwa Lake. Journal of Korean Society of Coastal and Ocean Engineers, 29(5), 247-259.

https://doi.org/10.9765/KSCOE.2017.29.5.247

Cavanagh, D., Dalrymple, B., \& Wood, M. (2006). Managing water quality in the Richmond River Estuary, Australia. In $9^{\text {th }}$ International River Symposium \& Environmental Flows Conference. Brisbane, Australia. https://citeseerx.ist.psu.edu/viewdoc/download?doi=10.1.1.656.4465\&rep=rep1\&type=pdf

Chai, F., Dugdale, R. C., Peng, T. H., Wilkerson, F. P., \& Barber, R. T. (2002). One-dimensional ecosystem model of the equatorial Pacific upwelling system. Part I: Model development and silicon and nitrogen cycle. Deep Sea Research Part II: Topical Studies in Oceanography, 49(13-14), 2713-2745. https://doi.org/10.1016/S0967-0645(02)00055-3

Chai, F., Jiang, M., Barber, R. T., Dugdale, R. C., \& Chao, Y. (2003). Interdecadal variation of the transition zone chlorophyll front: A physical-biological model simulation between 1960 and 1990. Journal of Oceanography, 59(4), 461-475. https://doi.org/10.1023/A:1025540632491

Chai, F., Jiang, M. S., Chao, Y., Dugdale, R. C., Chavez, F., \& Barber, R. T. (2007). Modeling responses of diatom productivity and biogenic silica export to iron enrichment in the equatorial Pacific Ocean. Global Biogeochemical Cycles, 21(3), GB3S90. https://doi.org/10.1029/2006GB002804

Jeong, S. I., Ryu, K. H., \& Lee, S. O. (2017). Numerical sensitivity analysis on hydraulic characteristics by dredging in upstream of abrupt expansion region. Journal of the Korean Society of Safety, 32(4), 46-52.

https://doi.org/10.14346/JKOSOS.2017.32.4.46

Jeong, S. I., Ryu, K. H., Jung, Y. H., \& Lee, S. O. (2018a). Optimal management of water level for water quality security in Saemangeum Basin. Journal of the Korean Society of Hazard Mitigation, 18(5), 301-309.

https://doi.org/10.9798/KOSHAM.2018.18.5.301

Jeong, S. I., Yoo, H. J., Ryu, K. H., \& Lee, S. O. (2018b). Numerical simulation for river safety of Saemangeum Basin according to Master Plan. Journal of the Korean Society of Safety, 33(5), 127-133. https://doi.org/10.14346/JKOSOS.2018.33.5.127

Jeong, Y. H., \& Yang, J. S. (2015). The long-term variations of water qualities in the Saemangeum salt-water lake after the sea-dike construction. Journal of the Korean Society for Marine Environment \& Energy, 18(2), 51-63.

https://doi.org/10.7846/JKOSMEE.2015.18.2.51
Jinqiong, Z., Yuan, Y., \& Xue, L. (2020). Impact of tide gate operation on sediment and water quality of Yongding New River. In K. Nguyen, S. Guillou, P. Gourbesville, \& J. Thiébot (Eds.), Springer water. Estuaries and coastal zones in times of global change (pp. 755-763). Springer, Singapore.

https://doi.org/10.1007/978-981-15-2081-5_44

Kim, S. M., Park, Y. K., Won, C. H., \& Kim, M. H. (2016). Analysis of scenarios for environmental instream flow considering water quality in Saemangeum watershed. Journal of Korean Society of Environmental Engineers, 38(3), 117-127. https://doi.org/10.4491/KSEE.2016.38.3.117

Korea Rural Community Corporation. (2006). Report for environmental effect on reclamation of Saemangeum.

Korea Rural Community Corporation. (2012 2015). Enverionmental survey report for Saemangeum district.

Korea Rural Community Corporation. (2016). Enverionmental survey report for Saemangeum district.

Korean Government. (2011). Saemangeum master plan.

Li, T., \& Kim, G. (2019). Impacts of climate change scenarios on non-point source pollution in the Saemangeum Watershed, South Korea. Water, 11(10), 1-19. https://doi.org/10.3390/w11101982

Liu, Q., Chai, F., Dugdale, R., Chao, Y., Xue, H., Rao, S., Wilkerson, F., Farrara, J., Zhang, H., Wang, Z., \& Zhang, Y. (2018). San Francisco Bay nutrients and plankton dynamics as simulated by a coupled hydrodynamic-ecosystem model. Continental Shelf Research, 161, 29-48. https://doi.org/10.1016/j.csr.2018.03.008

Lenton, T. M., \& Watson, A. J. (2000). Redfield revisited: 1. Regulation of nitrate, phosphate, and oxygen in the ocean. Global Biogeochemical Cycles, 14(1), 225-248. https://doi.org/10.1029/1999GB900065

Manasrah, R., Raheed, M., \& Badran, M. I. (2006). Relationships between water temperature, nutrients and dissolved oxygen in the northern Gulf of Aqaba, Red Sea. Oceanologia, 48(2), 237-253. http://www.iopan.gda.pl/oceanologia/482manas.pdf

Minh, H. V. T., Kurasaki, M., Ty, T. V., Tran, D. Q., Le, K. N., Avtar, R., Rahman, Md. M., \& Osaki, M. (2019). Effects of multi-dike protection systems on surface water quality in the Vietnamese Mekong Delta. Water, 11(5), 1-23.

https://doi.org/10.3390/w11051010

Ministry of Environment, Republic of Korea. (2019). Framework act on environmental policy. https://elaw.klri.re.kr/eng_mobile/viewer.do?hseq=44666\&type $=$ part \&key=39

Mirza, I. A., \& Vieru, D. (2017). Fundamental solutions to advection-diffusion equation with time-fractional Caputo-Fabrizio derivative. Computers \& Mathematics with Applications, 73(1), 1-10. https://doi.org/10.1016/j.camwa.2016.09.026

Oda, Y., Nakano, S., Suh, J. M., Oh, H. J., Jin, M. Y., Kim, Y. J., Sakamoto, M., \& Chang, K. H. (2018). Spatiotemporal variability in a copepod community associated with fluctuations in salinity and trophic state in an artificial brackish reservoir at Saemangeum, South Korea. PloS One, 13(12), 1-18. https://doi.org/10.1371/journal.pone.0209403

Park, Y. C., Park, J. K., Han, M. W., Son, S. K., Kim, M. K., \& Huh, S. H. (1997). Biogeochemical study of dissolved organic and inorganic compounds under oxic/anoxic environment in Lake Shihwa. The Sea, 2(2), 53-68. http://www.koreascience. or.kr/article/JAKO199734141858302.page

Quirós, R. (2003). The relationship between nitrate and ammonia concentrations in the pelagic zone of lakes. Limnetica, 22(1-2), 37-50. https://www.researchgate.net/publication/242422416_The_relationship_between_nitrate_and_ammonia_concentrations_in_the_pelagic_zone_of_lakes 
Ryu, K. H. (2018). A study on integrated water management of Saemangeum for environmental changes [PhD Thesis, Hongik University]. Seoul, Korea.

Saadatpour, M. (2020). An adaptive surrogate assisted CEQUAL-W2 model embedded in hybrid NSGA-II_AMOSA algorithm for resorvoir water quality and quantity management. Water Resources Management, 34, 1437-1451. https://doi.org/10.1007/s11269-020-02510-x

Stuyfzand, P. J., De Lange, W. J., \& Zindler, J. A. (2004). Recognition, dating and genesis of fresh and brackish groundwaters in the Hollandsch Diep estuary in the compound RhineMeuse delta. In Proceedings of the $18^{\text {th }}$ Salt Water Intrusion Meeting (SWIM), Cartagena, Spain (pp. 665-678).

Suh, S. W., \& Cho, W. H. (2007). Hydraulic change analysis on Saemangeum reservoir after final closure. Journal of The Korean Society of Civil Engineers, 27(3B), 361-369.

Suh, S. W., \& Lee, H. Y. (2008). Water quality simulations after completion of Saemangeum reservoir construction. Journal of the Korean Society of Civil Engineers, 28(1B), 79-93.

Umlauf, L., \& Burchard, H. (2003). A generic length-scale equation for geophysical turbulence models. Journal of Marine Research, 61(2), 235-265. https://doi.org/10.1357/002224003322005087

Wang, F. C. (1984). The dynamics of a river-bay-delta system. Journal of Geophysical Research: Oceans, 89(C5), 8054-8060. https://doi.org/10.1029/JC089iC05p08054

Wang, Z., Chai, F., Dugdale, R., Liu, Q., Xue, H., Wikerson, F., Chao, Y., Zhang, Y., \& Zhang, H. (2020). The interannual variabilities of chlorophyll and nutrients in San Francisco Bay: A modeling study. Ocean Dynamics, 70(8), 1169-1186. https://doi.org/10.1007/s10236-020-01386-0

Weng, X., Jiang, C., Zhang, M., Yuan, M., \& Zeng, T. (2020). Numeric study on the influence of Sluice-Gate Operation on Salinity, nutrients and organisms in the Jiaojiang River Estuary, China. Water, 12(7), 2026. https://doi.org/10.3390/w12072026

Yokoyama, T., \& Kyozuka, Y. (2003). Experimental study on flow and tidal exchange of a reservoir through dike gates in Isahaya Bay. In The Thirteenth International Offshore and Polar Engineering Conference (pp. 331-337). International Society of Offshore and Polar Engineers.

Zhang, Y. J., Ateljevich, E., Yu, H. C., Wu, C. H., \& Jason, C. S. (2015). A new vertical coordinate system for a 3D unstructured-grid model. Ocean Modelling, 85, 16-31. https://doi.org/10.1016/j.ocemod.2014.10.003

Zhang, Y. J., Ye, F., Stanev, E. V., \& Grashorn, S. (2016). Seamless cross-scale modeling with SCHISM. Ocean Modelling, 102, 64-81. https://doi.org/10.1016/j.ocemod.2016.05.002

Zigic, S., King, B., \& Lemckert, C. (2005). Modelling the twodimensional flow between an estuary and lake connected by a bi-directional hydraulic structure. Estuarine, Coastal and Shelf Science, 63(1-2), 33-41.

https://doi.org/10.1016/j.ecss.2004.11.001 